\title{
HOW DOES THE EFFECT OF COLOR IN MARKETING PROMOTIONS DIFFER ACROSS LATINOS IN THE UNITED STATES?
}

A SENSORY MARKETING STUDY

FABY CHAILLO GLOBAL COMMERCE SCHOLAR Distinguished Major Thesis 


\section{ABSTRACT}

Color is a tool used by marketers to communicate messages about their products and brands. These messages are interpreted by consumers on a conscious and subconscious level through a process of perception. This perception is important for companies as it encourages consumers to act upon their attitudes and emotions through product evaluations, purchases, recommendations, and more. However, the process in which humans form perceptions differs for everyone as it is highly affected by learned associations like culture. With increasingly global markets and a rising intercultural United States population, it is important to understand the effect of these sensory cues and how perceptions differ across different cultures.

This study focuses on the Latino population in the US, as it is the largest and fastest growing minority segment with a purchasing power of $\$ 1.5$ trillion. Specifically, it studies the interactive effect of culture and chroma, or brightness in color for this consumer group, and how that affects brand attitude, purchase intent, and ad recall. Based on extensive research and cultural premises, this study hypothesized that Latinos would have more favorable attitudes and behaviors in reaction to higher chroma ads, as compared to Americans. However, the interaction was not significant, with only the main effect of culture resulting statistically significant.

This result means that culture affected attitude and behavior such that Latinos had more favorable brand attitudes and higher purchase intent for the product after viewing the ad, regardless of chroma or hue. Additionally, the mediation effect for positive affect was significant, meaning that Latinos reacted more positively emotionally to the ad than Americans, which is what drove their more favorable attitudes and behavior. These research findings open up a lot of development areas for identifying what influenced that positive affect, to the extent of impacting their behaviorsomething that is really valuable for marketers to act upon. 


\section{ACKNOWLEDGEMENTS}

I would first like to thank my thesis advisors Associate Professor Nicole Montgomery and Associate Professor Amanda Cowen of the McIntire School of Commerce at the University of Virginia. These advisors were extremely helpful to me throughout the project. They were always happy to meet with me when I ran into obstacles or questions about my research or writing. They also taught me the structure and methods for academic writing and analysis. They consistently allowed this study to be my own work, but steered me in the right the direction as I needed it. I am very grateful for their valuable support throughout my time at McIntire.

I would also like to thank the director of the Global Commerce Scholar Program, Professor William Wilhelm and Assistant Dean for Global Affairs, Chris L.W. Elliot for leading me in the right path through this program and the seminars they set up for us. It is their passionate input that makes this program successful and my undergraduate research possible.

With special fondness, I must express my very profound gratitude to my parents for providing me with unfailing support and continuous encouragement throughout my years of study and through the process of writing this thesis. I would not be who I am without them.

Finally, thank you also to my sisters and boyfriend for the countless smiles and fun breaks from this project throughout the year.

This accomplishment would not have been possible without the support of these special people. Thank you.

Faby Chaillo 


\section{INTRODUCTION}

Color is an important sensory cue that marketers use as a tool to communicate messages about products and brands. These messages are interpreted from the physiological and psychological processes that result in different emotional and cognitive reactions (Hevner 1935; McCracken 1988; Schmitt and Simonson 1997; Ward 1995 as cited in Labrecque et al. 2013). These interpretations or perceptions matter to companies because they create emotions that influence behavior like product evaluations, purchasing, and recommendations. These perceptions also vary as humans learn associations, at a subconscious level, differently in their cultures. As brands become more global and international markets more interconnected, marketers need to be able to recognize cultural differences in perceptions to strategize marketing plans that will positively influence cognitive and emotional behavior of people across these different cultures. To address this issue, this research studies the effect of colors in promotions across different cultures. Specifically, it focuses on how Latinos perceive colors different than Americans in the United States.

Colorimetry is "the science and technology used to quantify and describe physically the human color perception" (Ohno 2000). Color perception matters in marketing as color is a vital component of a brand's visual identity, and the value that is derived from how the "look and feel" contributes to brand image and recognition (Lightfood \& Gerstman, 1998 as cited in Labrecque et al. 2013). That is why color is an important tool that marketers use in corporate and brand-building cues, such as logos, packages, displays, and advertising to create, maintain, and modify brand images in consumers' minds (Schmitt and Simonson 1997, Schmitt and Pan 1994 as cited in Madden et al. 2000). This is evidenced through strong color associations to brands; for example, red is associated to Coke, blue to IBM, and green and white to Canada Dry (Kanner 1989 as cited in Madden et al. 2000). Product categories that have become associated with certain colors also help with recognition 
and familiarity that affects trust level and product evaluations. For example, green has adopted an environmental connotation while pink is often associated with breast cancer support. These associations have implications in a consumer's mind about a brand's position in the marketplace (Labrecque et al. 2013).

While there is a vast amount of research on color and its implications to meaning and emotions conveyed, assuming all people perceive color the same way is simplistic and flawed. While humans perceive color through biological and physiological processing, as well as learned psychology, the learned psychology varies greatly between cultures. This ignites the question of whether color perception and its effect on meaning, emotions, and behavior changes across different cultures.

The effects of culture on color associations are critical for international marketers making decisions on culture-customized or standardized strategies for their brands (Schmitt and Pan 1994, as cited in Madden et al. 2000). It is the "choice between adopting a global versus a local approach in international marketing [that] often determines the success of a venture" (Aslam 2006 citing Dunn 1976; Shaw 1987; James and Hill 1991; Kanso 1992; Papavassiliou and Stathakopoulos 1997). For example, Pepsi lost its dominant market share to Coca-Cola in Southeast Asia when it changed its colors from "regal" blue to "light ice" blue, a color associated with death and mourning in Southeast Asia (Neal et al 2002 cited by Aslam 2006).

This phenomenon of differenced color perception becomes more relevant as countries' populations become so culturally diverse that multiple ethnicities are highly represented locally. For example, Hispanics are the biggest minority segment in the US, accounting for almost a fifth of the population, yet, there is very little known about how this consumer segment is influenced by color. There lies a question of whether their roots and background affect the way they perceive color and 
how that might affect their behavior, like purchasing or evaluating brands. This is what my research focuses on, considering there has been work done on other cultures, but not on this important segment. It can be hypothesized from the rest of the research that there are significant variations for this consumer group due to different learned cultural associations.

The following section presents the research done within the field of sensory marketing that is relevant to the question of the effect of color in promotions across different cultures. The basic understanding of sensory marketing is first established, then the scientific properties of color. After that, the review discusses human processing and the meanings associated with color. Lastly, the research section presents the secondary findings of cultural differences of color perception and interpretation. This will establish a well-rounded background for the understanding of the development, design, analysis, and results of this study. 


\section{PRIOR RESEARCH}

\section{Sensory Marketing}

Sensory marketing is defined as "marketing that engages the consumers' senses and affects their perception, judgment, and behavior" (Krishna, 2012). "Sensory" refers to the identification of a

sense being stimulated, while "sensual" refers to the gratification of that feeling (Krishna, 2011). The five senses are haptics, olfaction, taste, audition, and vision. In sensory marketing, the goal is to stimulate these senses to create subconscious triggers that influence consumer perceptions of abstract notions, like product quality or brand interactivity, that make up a brand's image or personality. It is commonly believed that these sensory triggers result in consumers' self-generation of perceptions that more effectively influence behavior in comparison to advertisements verbally communicating the same ideas (Krishna 2012).

Extensive research has been done in this area across all five senses, but vision has been established as the most influential sense. Within haptics, studies have determined that people with high need for touch are more likely to buy and be satisfied with a product they can touch before purchasing. Within olfaction, studies found that pleasant scents can enhance evaluations of products and stores. Within audition, brands have proved to have more positive ratings when their brand name sounds as expected (Krishna 2012). These are just a few examples of the power of sensation triggers in perception and behavior; more will be discussed about vision, particularly color perception. But within the field, it is important to note that visual triggers have exhibited dominance over other senses in their effect on perception. One example of this is an experiment conducted by Hoegg and Alba (2007) in which consumers taste three orange juice samples, two of the same, brighter color than the third, dull-colored juice. One of the bright-colored samples is the same juice as the one with dull color, with the color just manipulated to look different. The result showed that 
color was more instrumental in driving perceptions of taste than taste itself, as people identified the similar colored ones to be the same juice (Krishna 2012). Other studies have determined vision's dominance over touch through vision-touch discrepancy tests (e.g. Miller, 1972 cited by Krishna 2012). This dominance of vision for perceptions within sensory marketing accentuates the importance of studying aspects of vision that influence consumers, like color. To understand human perception of color, it is important to learn the basic science of color before learning the human side of color processing.

\section{The Science of Color}

The physical world has no colors. Colors are just different wavelengths of light waves. Longer wavelengths are the colors typically called "warm" like red and orange, and shorter wavelengths are the "cool" colors like blue and purple (Aslam 2006). Since Netwon's first theory of color in 1730 , colors have been described by a prismatic spectrum of hues arranged in a circular formation in relation to the three primary colors: red, blue, and yellow. Today, the most widely approved system is the Munsell Color Space. As seen in Figure 1, it describes the 10 main colors

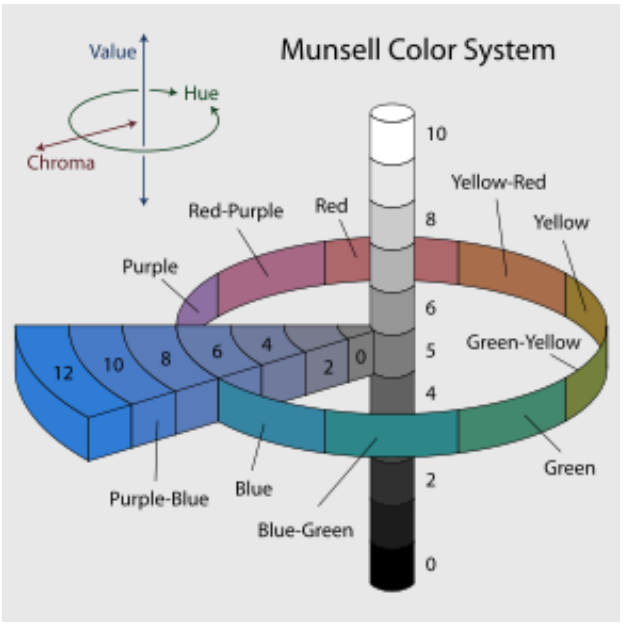

Figure 1: Munsell Color Space System on 3 dimensions: Hue, Value, and Chroma based on its three properties or dimensions: 1) Hue 2) Value 3) Chroma. Hue measures the pigmentation of a color, and it is what we usually name "colors" (i.e. red, blue, yellow). Chroma is the saturation level, ranging from $100 \%$ saturation, or a $100 \%$ pure color, to a $\% \%$ saturation, which is gray. High chroma colors are described as pure, rich, deep, vivid, or bright, versus low chroma as dull, washed out, or soft. Lastly, value indicates the light intensity, ranging from 100\% or fully 
illuminated (white/light) to $0 \%$ illumination (black and dark). Original color hues have an average lightness value of 50\% (Gorn 1997).

As expected by our common use of colors, much of color research focuses solely on hue, and neglects to investigate, or even control for the two other properties, value and chroma. However, it is important to investigate those dimensions as they have proven to have effects on perception and emotional reactions. For example, as a couple researchers have confirmed, Gorn (1997) found that ads with higher saturation lead to feelings of excitement or arousal, and ads with higher value lead to feelings of relaxation. He studied this through a paint advertisement experiment, in which no symbolism was associated with the product. The resulting emotional attitudes resulted in both increased likeability and memory of the ad-behavioral responses. This shows the importance of investigating and controlling for all three properties of color, not just hue.

\section{Processing of Color}

The human processing and perception of color is a set of subconscious stages that happen in the brain in milliseconds. It is important to understand because it allows for clearer definitions of what the marketer can and should influence to affect consumer attitudes and behaviors. Additionally, perception is important because it can vary greatly with sensory influencers, like color. How much perception differs in response to these influencers varies greatly, but even to extremes, like an entire culture, the Ndembo in Zambia, not being able to see the color hue orange as a separate color (Tektronix 1998 cited in Madden et al).

The processing of color, or any other sense trigger, occurs through physical and psychological factors that lead to perception of the color (Krishna 2012). This perception then influences behavior and attitude which is what businesses ultimately care about. To understand this 
process, visually presented in Figure 2, it is necessary to distinguish between sensation and perception, and cognition and emotion.

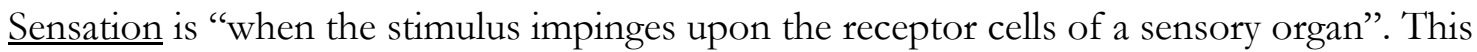
is a biochemical and neurological process. Perception is "the awareness or understanding of sensory information", or the construal or meaning of the color. Perception is influenced by emotion and cognition, and those psychological aspects in turn, are also affected by perception in an interdependent relationship (Krishna, 2012). This framework allows a deeper understanding of how color perception is influenced by physical sensation, and psychological emotion and cognition. The framework is a merger of Krishna (2012) and Lacrecque's (2013) ways of structuring the processing of color, and it integrates many research studies' findings.

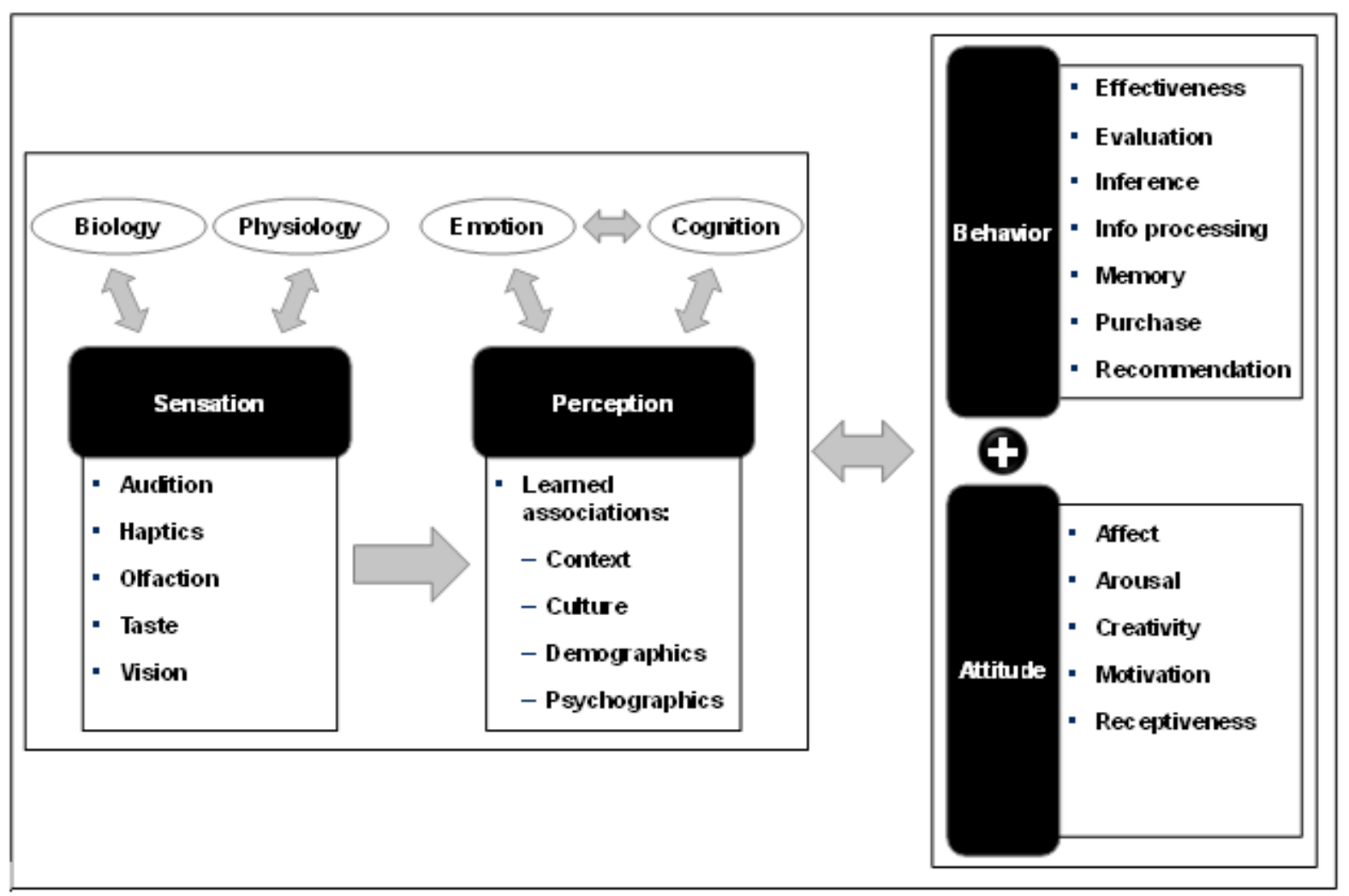

Figure 2: Color Processing Framework developed as an integration of Krishna (2012) and Lacrecque's (2013) 
Sensation is the biochemical and neurological process of recognizing a sensory trigger through the receptor cells of our organs. It is influenced by biology and physiology. For example, the chances of being color blind are higher for men than women due to biological compositions of the genders. Additionally, if a person has an accident that damages his/her retina, it will affect the way he/she senses color, physiologically. Biological responses to color cannot be learned, but rather people are born with them; they are "product of evolution and central to survival" (Mollon, 1989 as cited in Labrecque et al 2013). The easiest way to comprehend the process of sensation is with haptics. When a hot item touches humans' skin (an organ), the receptor cells underneath the skin cells sends a message to the brain (the neurological part of the process) that then releases chemicals to deal with the pain (the biochemical part). In the visual sensation of color, the retinal cones distinguish among different bands of light to determine hues (Aslam 2006). Color detection then stimulates the neural portion of the optical pathway, sending messages to the hypothalamus and then the pineal and pituitary glands, which control the endocrine or hormonal system. Empirical work by various researchers has demonstrated physiological effects of colors in human, affecting heart rate, respiration rate, blood pressure, muscle activation, and more (Mahnke, 1996, review by Bellizzi, Crowley, \& Hasty, 1983, cited by Labrecque et al 2013). For example, different light wavelengths affect the release and suppression of melatonin (the sleep chemical). Brainard et al (2008) found that blue's wavelength suppress melatonin production, promoting wakefulness, more strongly than the wavelength of violet (Kirshna 2011). Crowley (1993) also found that longer wavelengths, like red, result in arousing physiological responses, like increased brain activity and heart rate, more than shorter wavelengths, like blue (Labrecque et al 2013). This is relevant to marketers because increased brain activity and heart rate lead to better memory recall, which is desirable for brands. 
Perception is also influenced by the psychological components, emotion and cognition. The two are a function of external associations, like demographics (i.e. age, geographic area), psychographics (personal preferences and experiences), and learned associations like culture. These learned associations “emerge from an individual's network of semantic associations" and these associated meanings are paired with colors encountered in those constructions (Lacbrecque 2013). Hoegg and Alba (2008) have also found that cultural aesthetic differences can alter learned color associations and, therefore, product evaluation (Lacbrecque 2013). Another example of a cognitive aspect that influences perception of color is context. Context has been studied and found to play a significant role in determining the meaning of color. For example, red in a woman's cocktail dress at a dinner party versus red of the street stop sign trigger very different emotions. Red is the key color in both scenarios, but contextual inputs result in very different feelings of attraction and excitement versus avoidance and danger (Mahnke, 1996 as cited in Lacbrecque 2013). This goes to show why understanding how perception is formed is important for marketers, so they can consider all the external associations that their customers will encounter. Marketers will be able to influence some associations, like purchasing context and emotional messages from advertisements; other associations, they will just have to understand and work with to their advantage, like cultural traditions.

Perceptions, influenced by sensation, emotion, and cognition, lead to human behavior and attitude towards a brand, ad, or product. Emotion is a natural instinctive state of mind deriving from one's circumstances. Cognition is "the mental process of acquiring knowledge and understanding through thought, experience, and the senses" (Krishna, 2012). Both, rational understanding and instinctive emotions, affect the way humans perceive everything they sense. It is important to note that the factors that influence perception do not act in isolation; these interactions are depicted in Figure 2, using arrows, which show areas of interdependence (Lacbrecque 2013). So the combination 
of emotion, cognition, and perception (which are also influenced by sensation) lead to behavior and attitude. Behavior includes all the actions that can be taken and affected by the perception, like purchasing the product, evaluating it highly, or recommending it to another potential consumer.

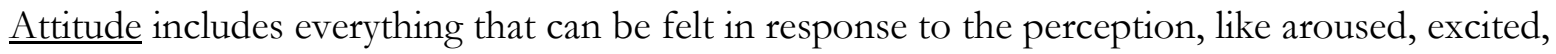
relaxed, etc. (Lacbrecque 2013). Attitude differs from emotion in that it has to be a result of the perception, although these factors interact to affect further perceptions. Attitudes are important for marketers because they interact with behavior to affect future perception and behavior. It is important to remember that these are all unconscious effects. While consumers might have some awareness of color associations, most of the time, the activation of this process happens subconsciously, and thus has an automatic influence (Elliot et al 2007 as cited in Lacbrecque 2013).

\section{Meaning of Color}

Through the perception process just described, people associate meaning to color. It is widely accepted that colors can influence emotions, thoughts, moods, and behaviors (Krishna 2011, Labrecque et al 2013). In fact that is why "artists have, for centuries, used color in attempts to convey certain emotions and mood in their work", giving the work meaning through the use of color (Gorn et al 1997, as cited in Krishna 2011). There is a wide variety of research sought to understand what these meanings are. Most of these have been done absent of any cultural context consideration, although the majority drew their populations from Western pools.

Some universal color meaning and emotional responses include gray being associated with strength, exclusivity, and success; orange with cheapness; purple with stately; yellow with cheerful, joyful, and jovial; and black with powerful, strong, and masterful. (Wexner 1954 as cited in Madden et al 2000). Furthermore, many findings show that warm colors increase arousal, whereas cool colors 
tend to induce feelings of relaxation and perceptions of pleasantness (Bellizzi, Crowley, \& Hasty, 1983; Bellizzi \& Hite, 1992 as cited in Labrecque et al 2013). Because of their similarities in natural value and chroma, but extreme differences in hues, red and blue have been deeply studied. Findings show that blue is associated with relaxation, tender-soothing, wealth, trust, and security. Blue activates an approach motivation which leads to more stimulated purchases, favorable evaluations, fewer purchase postponements, and a stronger inclination to shop and browse, in comparison to red (Mehta and Zhu 2009, Bellizzi and Hite 1992 as cited in Lacbrecque 2013). Red, on the other hand, has been interpreted as arousing, exciting, and attention-grabbing, which leads to increased attention, memory, and favorable evaluations of prevention-focused ads (Mehta and Zhu 2009, Bellizzi and Hite 1992 as cited in Lacbrecque 2013).

Background colors have shown to alter product perceptions, such as elegance and uniqueness (Middlestadt 1990 as cited in Lacbrecque 2013). Additionally, another study showed that the background color of a website affected the users' relaxation, which affected perceived loading time. The perceived loading quickness affected user evaluations and their likelihood to recommend the website (Gorn, Chattopadhyay, Sengupta, and Tripathi 2004, Middlestaft 1990 as cited in Lacbrecque 2013). Lastly, even the atmospherics can influence purchase behavior with the change of color. Colors in the interior and exterior of stores, display cases and signs, and even store personnel's uniforms can influence attention-grabbing, message-creation, and affect-creation behaviors. Kotler's research (1973) suggests that cool colored store environments are preferable to warm colored environments (Babin, Hardesty, \& Suter 2003, Bellizzi, Crowley, \&Hasty 1983, Crowley 1993 as cited in Lacbrecque 2013). These color influences in emotions and behavior are relevant to marketers who want to improve customer retention and attraction to a brand. 
Since colors have associated meanings to them, people naturally cluster colors by similar meaning associations. Madden et al (2000) studied color meaning associations throughout cultures and blue, green, and white were universally clustered together, with the meanings of peaceful, gentleness, and calm. Black and brown were also clustered together with meanings of sadness and staleness. Gold, orange, and yellow were often, but not always clustered together, and red was the one color that tended to not be clustered with others universally. Red portrayed meanings of activity, hotness, and vibrancy (Madden et al 2000). These color cluster meanings can be used by marketers for logos, advertisements, and branding based on the meanings they want associated with their products.

\section{Cultural Differences in Color}

As discussed previously, colors have meanings associated to them from human perceptions that were influenced by the sensory processing of the color, as well as cognitive and emotional influencers. These psychological influencers, as well as the learned associations already discussed are what lead to color meanings. Culture is a big influencer within those learned associations, which is why some research has focused specifically on investigating how color perception differs across cultures, even though the physiological structures responsible for color vision in humans are universal (Davidoff 1991 as cited in Gorn et al). Evidence from these color studies in the context of culture suggests that there are significant cultural differences in color association and preferences (Philbrick 1976, Trueman 1979, Block \& Kramer 2009, Hewett \& Roth 2000, as cited in Madden 2000).

These differences in color perceptions across cultures are not surprising as "nearly every race, religion, and culture has definite ideas about the importance and application of color and has 
used it to differentiate and attach meaning to objects." A clear example is the use of blue and indigo for royalty and important religious figures, such as the Virgin Mary (Labrecque et al 2013). Color has been a cultural aspect since the medieval and renaissance religious symbolism, in which cardinals' dress colors represented different meanings of celebration or mourning. Hindus and Buddhist monks also show a similar use of color, with orange being the sacred hue (Aslam, 2006).

These cultural associations led to many researchers testing the hypothesis that culture has an effect on color perceptions. An early key experiment of color associations sampled people in Jerusalem in 1941 , who revealed that $86 \%$ of Jews had a strong negative association with the color yellow, the color used as an identifier of Jews by the Nazis at the time. Twenty years later, when the replication of the study happened, only $41 \%$, less than half of the original results made the same association. This was explained by Kreitler \& Kreitler (1972) as a cultural explanation to the change in color perception (Aslam 2006). Across various findings with different testing methodologies and other varied factors under the context of color, there has been a reoccurring "blue phenomenon" that describes the universal preference for blue across cultures, and its meaning association to high quality and relaxation (Jacobs 1991, Simon 1971, Wiedgersma \& Van der Elst 1988 as cited by Madden et al 2000). Furthermore, black is associated with expensiveness and power, and red with love across all cultures. However, red signifies happiness to Chinese people, which explains its common use of the color for wedding invitations (Madden et al 2000). Red is also associated with soft drinks usually, but in Korea and Japan the association of soft drinks is with yellow and in China with brown (Jacob et al 1991 as cited in Aslam 2006). Another example is the perception differences of expensive brands in the US versus Asia. Asian countries associate purple with expensive, where Americans actually perceive purple as inexpensive. Americans perceive gray as expensive, high tech products, where as China views that color as inexpensive (Stanton et al 1994, Jacobs et al 1991 as 
cited in Aslam 2006). Other associations of colors throughout different cultures can be seen in Exbibit 1.

Although very limited work has been done with color in the context of culture for the Hispanic population, early evidence suggests that this minority group gives particular importance to color when purchasing. Akcay et al. (2012) found that $60 \%$ of teenage Hispanics identified color as an important factor in purchasing decisions, compared to $20 \%$ of African American and Caucasian American teenagers. Hispanics' importance given to color in purchases further accentuates the need to study this segment's color perceptions and meanings, emotions, and behavior that follows. However, there are no indications of any research on color meaning and perceptions by Hispanic Americans in the US. This segment is important as it accounts for $17.6 \%$ of the US population, with the fastest growing rate of a single minority segment (US Census). Hispanics in the US carry a strong purchasing power of $\$ 1.5$ trillion - a total larger than Mexico’s GDP - with an $8 \%$ annual growth rate (Nielsen State of the Hispanic Consumer 2012). The growing relevance of this consumer population indicates that this is a demographic group worth investigating, for marketers to understand their perceptions and meaning of color. These are the reasons why the focus of this research is on how color perceptions vary between Latinos and Americans in the US. The previously presented findings on color perception differences between cultures leads to my expectation that cultural differences in this group also lead to significant variation in color preferences, meaning associations, and behavior.

\section{Research Limitations}

After understanding and presenting the research that has been done in this field of sensory marketing and particularly the perception and meaning of color association, it is important to 
consider the limitations of this secondary research in order to improve the quality of future studies. Some limitations to look out for are the lumping of colors into categories like warm versus cool when studying hue, since additional hues risk being neglected, and that ignores the multitudinous subtleties in the spectrum of colors. Also, it is important to control lighting conditions considering that lightness level is one of the main properties of color that affects physiological perceptions. Additionally, it is important to measure and report specific values and multitudes of color spaces so that experiments can be replicated (Labrecque et al 2013). Another limitation is that large part of color research is done by internal companies or branding consulting firms that keep results unpublished because of competitive concerns. Because of this, the literature reviews in the scholar domain mostly examine academic experiments as opposed to results from the workforce. Finally, most research works exhibit a largely western focus, which is why it is important to continue investigating these effects of color across cultures around the world (Aslam, 2006). 


\section{FURTHER RESEARCH \& HYPOTHESES}

With the purpose of expanding cross-cultural color research, in this study I test for the effect of color perceptions across different cultures, particularly focusing on Latinos as compared to Americans in the United States. While there is a lack of research on Latinos and color, this segment is of particular interest given that Hispanics are the largest and fastest growing minority, and one with very strong consumer power. Many companies are trying to understand how they act and react to promotional cues differently than Americans, which is what my study aims to understand. I plan on developing insights about the Latino perception and reaction to color, as color is so prominent in their culture (Paul 2002). The study also examines how those perceptions translate into attitudes and behavior that will be relevant to companies when developing their marketing strategies.

The goal of my study is to identify differences in color perception in promotions for marketers to fight today's cluttered media and environment by being able to differentiate their products, brands, and advertisements by appealing to consumers on a customized level. An important result of this research would be for advertisers to be able to informedly "select colors that maximize attention, provide a more realistic and appealing portrayal of the product or service, and arouse appropriate feelings", so they can achieve favorable brand attitudes (Wells et al 1992).

\section{Color, Culture, and the US Latino Population}

Before addressing the interaction of the Latino culture with color, it is important to define Latino, Hispanic, and the different ethnonym terminology that is often used interchangeably. Hispanic refers to people of descent from a Spanish speaking country, which therefore includes Spaniards but not Brazilians, although they are Latin Americans. Latino, however, does refer to people of descent 
from a Latin American country. This is not to be confused with Latin, which refers to people of descent from a country whose language root is Latin, like the French and Italians (Robert). None of these terms refer to race, as people from Latin America vary widely in race with immigration from Europe, Africa, and Asia. Also, it is important to note that there is a huge intersection in the population of Latinos and Hispanics and the only non-inclusive people in both terms are Brazilians and Spaniards. So while most of the research is done on "Hispanics", it also applies correctly as a base to the research for the setup of this experiment. My research study is more specific, and focuses on Latinos, as it is the Latin American culture that is seen as one entity for a variety of reasons that unite the countries and its people.

The Latin American culture refers to both high culture (literature, high art, etc.) and popular culture (music, folk art and dance). This culture has been formed and developed by many influences, including the Pre-Columbian cultures, the European Colonial cultures, Trans-Atlantic Slave Trade from Africa, and the $19^{\text {th }}-20^{\text {th }}$ century immigration period. The Pre-Columbian Cultures, like the Mayans, Aztecs, and Incas influenced a lot of what remains in Latin America, and the wider world today, including science, language, religion, decorations, print and color dying techniques, etc. For example, the color orange as the signature of Halloween was born from the Zempaxichil flower used traditionally by the Mexicas Aztecs on the Day of the Dead. Furthermore, Latin American culture was highly influenced by the European Colonization, particularly seen in today's architecture, literature, painting, music, language, and other high culture aspects. Latin America was also influenced by the Trans-Atlantic Slave Trade from Africa that influenced a lot of popular culture today, including music, dance, and cuisines. Finally, 19-20 $0^{\text {th }}$ century immigration from Europe and between Latin American countries also influenced the mixing and merging of the culture as one. 
There is limited research on the significance of color to the Latino culture, but the work that has been done largely addresses Latinos' preference for brilliant colors. This preference can be attributed to a few different contributors like the history of color use in the Pre-Columbian Natives. These tribes were among the oldest, known humans to use color as a method of communication with associations of meaning to different color patterns, corporal art, and in cave and architectural iconography. Since then, natural flowers were used to paint color that is suspected to have been vibrant given their survival to this day in archeological sites (Dupey Garcia 2016). More recent literature on color in the Latino culture attributes the preference for intense and warmer colors to the environmental factors, even though there have not been experiments that test this theory. The Director of the Color Association of the United States, Margaret Walch, says it is a reflection of the intense lighting conditions from naturally stronger sunlight in those countries (Paul 2002). It is commonly said, while not tested, that "Hispanics usually are drawn to brighter, stronger, and more intense colors" (Paul 2002). In fact, as reiterated by the president of the Color Marketing Group, Jay de Sibour, warming up the palette by adding yellow and red tones is often recommended and done by marketers addressing the Latino segment (Korzenny 2009). Companies have followed this trend, as seen with Home Depot's product development of its new palette of paint colors aimed at Hispanic customers due to their high purchasing activity in this market. Home Depot added more vibrant colors named after Latin American references (i.e. Mango Jugoso, Mamey after a Latin American native bright peachy-orange fruit, etc.) (Finholm, 2005).

Due to these theories about historical, cultural, and environmental factors affecting the perception and associative meaning of color, I expected significant results in testing the interaction between ethnicity and color interpretation. Because experts refer to Latinos' color preference as bright, vibrant, and intense, I specifically test the chroma variation of color in print advertisements and its effect on Latinos' perceptions as compared to US-born Americans'. My expectation was, 
therefore, that Latinos would exhibit more favorable results in reaction to products presented in an advertisement with a higher chroma as compared to a lower chroma, where US-born Americans would not differ in their attitudes by ad chroma level variations. Specifically, the study's hypotheses are:

H1 a) Culture group and chroma will interact to affect products' brand attitude such that Latinos evaluating an advertisement with higher chroma will result in more favorable brand attitudes as compared to low chroma advertisements. This effect will not be significantly different for the US-born American population.

H1 b) Culture group and chroma will interact to affect purchase intent such that Latinos evaluating an advertisement with higher chroma will result in more willingness to purchase as compared to low chroma advertisements. This effect will not be significantly different for the US-born American population.

H1 c) Culture group and chroma will interact to affect ad recall such that Latinos evaluating an advertisement with higher chroma will result in better recall as compared to low chroma advertisements. This effect will not be significantly different for the US-born American population.

The prediction of more favorable results for Latinos evaluating high chroma advertisements stems from the assumption that a reminder of the subjects' native culture or country is a positive experience. I expected that Latinos would like the color, as an attribute of the brand, more with higher chroma levels. It is also assumed that positive feelings would subconsciously stem and result in favorable attitudes towards the products in the ads with a higher chroma. To test the validity of this proposed mechanism, I also developed mediation experiments that examine if either or both of the following hypotheses cause the results of the first. These hypotheses are: 
H2 a) As chroma level increases, Latinos' perception of the quality of color, as an ad attribute, will also increase. This effect will not be significantly different for the US-born American population.

\begin{abstract}
AND/OR
H2 b) As chroma level increases, Latinos' feeling/affect score after viewing the ads will also be more positive. This effect will not be significantly different for the US-born American population.
\end{abstract}

These second hypotheses allow for meaning and interpretation of the results of the first hypotheses. If the effects are in fact more favorable for higher chroma advertisements in the Latino population, then it is important to examine why the difference exists. Asking people how they like specific advertisement attributes and how they feel after viewing the ads gives further insight into this issue. My prediction was that either or both of the quality perception of color or the feeling after viewing the ad would be causes for the interaction between culture group and chroma. 


\section{METHODOLOGY}

This study's methodology is based on a set of theoretical decisions about the techniques used for this work. As the researcher following the Layers of Research Design from Saunders and Tosey (2013), I approach my study with a positivist philosophy, in which I use the scientific method of a controlled environment, where variables are manipulated to find results. The approach is deductive since the process is top down, first developing a theory and hypothesis from the studied research, and then designing the study to test and confirm results. The strategy for this study is to use an experimental design where data is collected using an online survey. The data is analyzed using a variety of empirical techniques including simple linear regression, multiple linear regression, and logistical regression statistical models. Finally, the time horizon is cross-sectional as comparisons are only made at a single point in time, rather than across time. The study design, data collection, and analysis techniques all stem from this philosophical methodology design.

\section{Study Design}

This study tests the aforementioned hypotheses using a 2 (Culture group: American vs. Latino) x 2 (Chroma level: high vs. low) x 2 (Color hue: warm vs. cool) study design. Thus, the design includes eight distinct combination groups of ideally 60 participants in each, as demonstrated in Exhibit 2-A. The addition of the color hue construct of warm vs. cool is used to control for hue preferences and predispositions, not as a main effect of interest in this study. The total pool is designed to be of 480 subjects, 240 Latinos and 240 Americans. Each culture group is designed to have 60 viewers of the low chroma, warm hue ad, 60 of the low chroma, cool hue ad, 60 of the high chroma, warm hue ad, and 60 of the high chroma, cool hue ad. The actual experiment ended up using a sample size of 158 Latinos and 231 Americans due to data collection limitations discussed in the limitations section at 
the end. For the survey, subjects are screened to be either 1) US-born Americans (simply called Americans moving forward) or 2) Latinos residing in the US who were born in Latin America. This requirement of birth in Latin America controls for cultural assimilation, as second generation immigrants are much less likely to have a strong Latino cultural connection (Bleakley, Chin 2010). Participants for the survey had to be 18 years or older for logistical payment issues, and there were no gender restrictions for subjects taking this online survey.

To develop the design further, the questionnaire tests these two cultural pools of subjects with two versions of the survey ad: a high chroma and a low chroma one. The high chroma level is of $100 \%$ saturation and the low chroma of $30 \%$ saturation, which is low, but still identifiable in the spectrum given that $0 \%$ would show no color. While all questions in the survey remain the same, half of each population randomly receives low and half high chroma level advertisements, as shown in Exbibit 2-B. Additionally, to control for different hue preferences and predispositions to the background colors, the study randomizes the version of the ad to show either a blue (a cool hue, with short wavelengths) background or an orange (a warm hue, with long wavelengths) background. For yoking purposes, the order of the multi-part questions are randomized to control for order selection biases in questions about feelings and ad attributes. Finally, after much research and thought, it was decided to leave out any instructions about computer or room lighting to avoid alluding to the purpose or interest of the study. It was determined that with the high sample size, the differences would naturally cancel out and control any lighting effects on the perception of color.

The advertisement used for this study shows dental floss as the selling product. It uses a modern approach to design where the background is simply one color and the attention is called to the content. The ad's content shows a kiwi "flossed" with its seeds spread around it. The product is shown on the bottom right with the branding "Shine" and four product attributes, "Deep Clean, 
Shiny Teeth, Mixt Waxed, [and] Medically Approved Dental Floss" mentioned below it. I chose the advertisement to display dental floss as it is a product that everyone uses and is not inherently associated with gender, income level, age, nor other demographics. Furthermore, there is no color association to dental floss. The brand name was created as a made-up brand to avoid brand preference effects in the results. The included brand attributes were developed from product category experts at the Academy of General Dentistry (2016). The different versions of the advertisement that were tested at the two chroma and hue levels can be seen in Exbibit 3 .

\section{Measures}

After displaying the ad in the survey, a series of question are asked to test for the dependent variables of interest. These dependent variables being tested in the study are: brand attitude, purchase intent, ad recall, perceived perception of quality of color as an advertisement attribute, and the subject's feelings after viewing the ad. The latter two are expected to be reasons for significant confirmations of the first set of hypotheses, or the first three dependent variables. Each construct or dependent variable is measured across a set of dimensions previously used by this research topic's experts. There are a few types of ad recall measures, testing for what attributes of the ad the viewer can remember; the dependent variables are: recall of the brand, recall of the product, recall of the ad content (kiwi), recall of any color, recall of the background color, and the recall of each of the four product attributes described, as well as a count of the attributes correctly recalled. Next, in ad attribute perception testing, the only variable hypothesized to have an effect is quality of color, as there is no theoretical basis for linking the other ad attributes (picture, text font, spacing, and wording quality) to the culture and chroma interaction; they were only included for sake of comprehensiveness. Similarly, while not all feelings listed are expected to be linked to advertisement 
reactions, this PANAS scale is a widely used measurement of current affect, and the listed attitudes are clumped accordingly to assess the subject's feelings (Watson, Clark, Tellegen 2016). Finally, basic demographics, age, gender, and household income, along with age of arrival to the US, current residency, and country of origin were measured as consistent with past work, and were only tested for additional correlation effects. At the end of the personal information section of the survey, the survey asks a question to screen out colorblind participants to avoid external color perception effects. The full set of survey questions, citations, and measurement scales is further developed in

\section{Exbibit 4.}

\section{Data Collection}

For this study, I collected data by conducting online surveys with Latinos and Americans through Amazon Mechanical Turk (MTurk). This is a crowdsourcing marketplace that gathers information intelligently from individuals and businesses in the US. This system has proven to be successful and a valuable tool for conducting rapid and inexpensive data collection. MTurk successfully addresses the comparison of private versus social domains and screens for attention and language comprehension measures. Its large pool allows the randomization of the pools, resulting in reliable and high quality data (Buhrmester, Kwang, Gosling 2011). Additionally, Huff and Tingley from Harvard (2015) have validated that MTurk is excellent at attracting a big Hispanic population, which facilitated drawing enough data to achieve significant results. Before launching the survey, I receiving approval from the Institutional Review Board for Social \& Behavioral Sciences by sharing the study's process and design and officially agreeing to the highest standards of ethic in the collection of data from human subjects. 


\section{Data Analysis}

The resulting data from the survey was analyzed on SPSS along different statistical tests for the five hypotheses stated previously. Given the 2x2x2 study design testing for culture, chroma, and hue, I analyzed the data in two parts: the first to test the main effects and interactions in the H1 set of hypotheses, and the second to test for mediators stated in the $\mathrm{H} 2$ hypotheses for the significant results in H1. The goal of this dualphase process is to understand any results from $\mathrm{H} 1$ by testing for $\mathrm{H} 2$ potential explanations, as seen in the

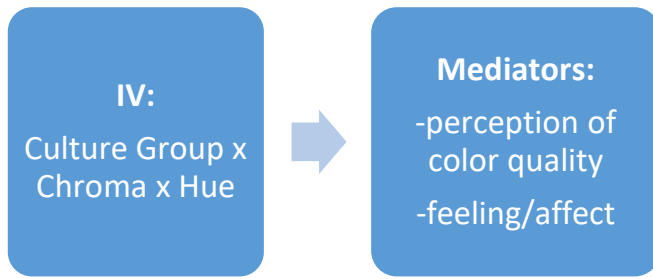

conceptual framework for the

Figure 3: Conceptual Framework for Hypotheses Analysis

hypotheses in Figure 3. Given the nature of the data, I performed multiple statistical tests, including simple linear regressions, logistic regressions, ANOVA (multiple linear regression) tests, and cross tabulations, to examine the effects in the hypotheses.

To test for the first set of hypotheses, this study first analyzes the main and interaction effects. The interactions examine the pattern of each independent variable at each level of the other independent variables, including the three way interaction. Therefore, I conducted regression tests to analyze any patterns displayed by Latinos across chroma and hue levels and how their patterns differ from those displayed by Americans across the same levels. This allowed me to compare the effects of the independent variables, culture group, chroma, and hue, on the dependent variables of brand attitude, purchase intent, ad recall, perceived quality of color as an ad attribute, and feelings after seeing the ads. The exact statistical models I ran were ANOVA, multiple regression analyses for the continuous dependent variables (Brand Attitude, Purchase Intent, and number of recalled attributes), and cross tabulations and binary logistic regressions for the dichotomous dependent 
variables (brand recall, product recall, ad content (kiwi) recall, color recall, background color, and the recall of each of the four product attributes). The ANOVA statistical test was possible by separating data into 7 distinct categories: 1) chroma, 2) culture group, 3) hue, 4) chroma x culture interaction, 5) chroma $\mathrm{x}$ hue interaction, 6)culture $\mathrm{x}$ hue interaction, and 7) the chroma $\mathrm{x}$ culture $\mathrm{x}$ hue, 3-way interaction. The regression models test for any significant relationships among these variables, with a model that includes the main effects alone, as well as the interactions. The three main effect columns distinguish values between the two levels by using dummy variables; for example, for chroma, 0 represented low, while 1 represented high. Similarly, the interaction columns multiplied across the main independent variables of interest to create binary 0 s and 1s. After distinguishing the data values in columns, I ran the regression tests including all the categories to look at the effect they have on the three $\mathrm{H} 1$ dependent variables with the regression equation based on this model:

$$
\begin{aligned}
& Y_{H 1}=\mathcal{B}_{1}(\text { Culture Group }) X_{1}+\mathcal{B}_{2}(\text { Chroma }) X_{2}+\mathcal{B}_{3}(\text { Hue }) X_{3} \\
&+\mathcal{B}_{4}(\text { Culture } x \text { Chroma }) X_{4}+\mathcal{B}_{5}(\text { Culture X Hue }) X_{5} \\
&+\mathcal{B}_{6}(\text { Chromax } \text { Hue }) X_{6}+\mathcal{B}_{7}\left(\text { Culture X Chromax Hue } X_{7}+\mathcal{B}_{0}\right.
\end{aligned}
$$

This regression analysis looks at these factors shown as $\mathcal{B}_{1}-\mathcal{B}_{7}$ to determine which are significant. Any relationship of a p-value equal or less than 0.05 is considered statistically significant, while anything between 0.05 and 0.10 is considered partially significant. Based on the resulting significance level of the factors, I was able to draw conclusions about the main (or collapsed) and the interactive effects of culture, chroma, and hue. As outlined in the hypotheses, and because of previous research, I hypothesized that only the interaction with chroma and culture group would be significant.

After H1 hypotheses tests, the H2 set of hypotheses were tested for mediation of any effects that were proven to be significant in the first analysis. The goal of this analysis was to determine if the perception of color quality as an ad attribute or feeling/affect after viewing the ad are the 
reasons why H1's main or interaction effects are significant. The expected relationships can be followed in Figure 3's framework. To test the effect of the mediators for relationships where the independent variable proved to significantly affect the dependent variable, I first ran the original model with the mediator as the dependent variable. This tests whether the effect determined the mediator, so the relationships between the first two boxes in Figure 3. This regression model is the same as the original, but with the mediator as $\mathrm{Y}$, as seen below:

$$
\begin{aligned}
Y_{H 2}=\mathcal{B}_{1}(\text { Culture Group }) X_{1}+\mathcal{B}_{2}(\text { Chroma }) X_{2}+\mathcal{B}_{3}(\text { Hue }) X_{3} \\
+\mathcal{B}_{4}(\text { Culture } x \text { Chroma }) X_{4}+\mathcal{B}_{5}(\text { Culture x Hue }) X_{5} \\
+\mathcal{B}_{6}(\text { Chroma } x \text { Hue }) X_{6}+\mathcal{B}_{7}\left(\text { Culture X Chromax Hue } X_{7}+\mathcal{B}_{0}\right.
\end{aligned}
$$

Next, to prove the mediation significant, I regressed the original H1 dependent variable onto the mediator now as the independent variable, or predictor. This tests the relationships between the mediators and the dependent variables or the second two boxes in Figure 3. The regression model is the following:

$$
Y_{H 1}=\mathcal{B}_{1}(\text { Mediator }) X_{1}+\mathcal{B}_{0}
$$

Finally for the mediation test, I analyzed the three way relationship with the original H1 significant effect and the $\mathrm{H} 2$ mediator proving to be significant on the $\mathrm{H} 1$ dependent variable. This tests the three boxes and directional arrows of the framework in Figure 3. The regression model is the following:

$$
Y_{H 2}=\mathcal{B}_{1}(\text { Significant Effect from } H 1) X_{1}+\mathcal{B}_{2} \text { (Mediator) } \boldsymbol{X}_{2}+\mathcal{B}_{0}
$$

In this model, I wanted to show that only the mediator is significant to prove a mediation effect as the validation for the $\mathrm{H} 1$ significant results. 
After testing main and interaction effects, as well as mediators for the significant ones, the data analysis for the hypotheses was concluded. For precision and comprehensiveness, I also regressed a few additional measures that were collected to examine any possible spectrum patterns, linear relationships, or outside effects. These additional variables were the amount of time living in the US, age, gender, income level, country of origin, and state of residence. 


\section{RESULTS}

The hypotheses in the study were tested through regression models, starting with the three H1 dependent variables (brand attitude, purchase intent, and ad recall) being regressed onto the three independent variables (culture, chroma, and hue) for both main and interaction effects. Then, I regressed the two $\mathrm{H} 2$ dependent variables (perceived quality of color as an ad attribute and feelings

after viewing the ad) onto the same independent variables and continued with a mediation proof for the H1 significant effects.

\section{Brand Attitude}

The dependent variable brand attitude was a measure averaging the results of three questions, where participants rated the brand on a scale of 1-7 for bad-good, unpleasant-pleasant, and unfavorablefavorable. I ran an ANOVA, multiple regression test to regress brand attitude onto culture, chroma, and hue on both main effects and interactions. Contrary to what was hypothesized in H1, no interaction effects proved to be significant. The 3 -way interaction resulted in statistics of $f(1,381)=$ 0.22, $\mathrm{p}=0.639$ and the culture $\mathrm{x}$ chroma interaction resulted in $\mathrm{f}(1,381)=1.089, \mathrm{p}=0.297$, neither one showing significant effect p-values. This means that chroma and hue do not impact differences in brand attitude for these two culture groups, as predicted in H1a.

However, culture group did reveal a significant main effect on brand attitude, such that Latinos reveal a more favorable brand attitude for the brand. The result of this main effect was significant with a $p$-value of $p<0.05$ and the statistics resulting in $f(1,381)=6.427, p=0.034$. This means that the Latino population had a higher mean in their attitude favoring the brand than Americans did, regardless of chroma or hue levels. While the H1a hypothesis was not supported, 
this finding is interesting and further investigated with the mediation effect to test for possible reasons of why Latinos like the brand better.

\section{Purchase Intent}

Similarly, the dependent variable purchase intent was a measure averaging the results of two questions, where participants rated their likelihood of purchase and seeking out the product on a scale of 1-7 from very unlikely to very likely. I ran an ANOVA, multiple regression test to regress purchase intent onto culture, chroma, and hue on both main effects and interactions. Contrary to what was hypothesized in $\mathrm{H} 1 \mathrm{~b}$, no interaction effects proved to be significant. The 3 -way interaction resulted in statistics of $\mathrm{f}(1,381)=0.013, \mathrm{p}=0.910$ and the culture $\mathrm{x}$ chroma interaction resulted in $f(1,381)=2.179, p=0.141$. This $p$-value was close to the partial-significance threshold, meaning that if the sample was larger, it could increase in significance and support the hypothesis. However, given this study's results, the effect is not sufficient to prove that culture, chroma, and hue impact purchase intent for these two culture groups, as predicted in $\mathrm{H} 1 \mathrm{~b}$.

However, culture group also revealed a significant main effect on purchase intent, such that Latinos reveal a higher likelihood of purchase for this product. The result of this main effect was significant with a $\mathrm{p}$-value of $\mathrm{p}<0.05$ and the statistics resulting in $\mathrm{f}(1,381)=16.52, \mathrm{p}=0.000$. This means that the Latino population had a higher mean in their likelihood of purchasing this product than Americans did, regardless of chroma or hue levels. While the H1b hypothesis was not supported, this finding is interesting and further investigated with the mediation effect to test for possible reasons of why Latinos are more willing to purchase the product. 


\section{Recall}

Recall was tested across a few different measures: brand recall, product recall, ad content (kiwi) recall, color recall, background color, recall of each of the four product attributes, and a count of how many of the four attributes participants recalled. The data was collected with an open-ended question asking for everything they recalled about the ad. The results were then complied into each measure with dichotomous $1 \mathrm{~s}$ and 0 s for whether they recalled the item of interest or not. The final count of attributes recalled was a sum of the four individual attribute columns. For the dichotomous recall measures, I ran cross tabulations and binary logistic regression tests to regress recall onto culture, chroma, and hue on both main effects and interactions. For the count of attributes recalled, I ran ANOVA, multiple regression tests to regress the same effects because the values were continuous. Contrary to what was hypothesized in H1c, no main or interaction effects proved to be significant. All $\mathrm{f}$ and chi-squared test statistics had $\mathrm{p}$-values greater than 0.10 , showing no significant effects. This means that chroma and hue don't impact differences in product recall for these two culture groups, as predicted in H1c.

\section{Perception of Color Quality as an Ad Attribute}

Next, I tested the dependent variable of perception of color quality as an ad attribute, as per hypothesis H2a. Even though more ad attributes were included in the question, they were added for comprehensiveness and to not allude to color being the attribute of interest. This dependent variable was measured on a -4 very bad to +4 very good scale about the quality of color in the ad. I ran an ANOVA, multiple regression test to regress perception of color quality as an ad attribute onto culture, chroma, and hue on both main effects and interactions. The only expected significance was for the main effect of ethnicity to prove an effect on perception of color quality as an ad attribute, as 
a mediation effect. However, the $\mathrm{p}$ value for this relationships was $\mathrm{p}=0.127$, which is not significant, but very close to the partial significance threshold. If the sample was larger, it could increase in significance, in which case color quality perception could prove to be a mediator for the culture group main effect. But ultimately, none of the main effects or interactions proved to be significant in this study, as they all had $\mathrm{f}$ statistics with $\mathrm{p}$-values greater than 0.10 . This means that perception of color quality as an ad attribute does not mediate the significant result of ethnicity on culture, as hypothesized in $\mathrm{H} 2 \mathrm{a}$.

\section{Affect}

The last dependent variable I measured was affect after viewing the ad, as per hypothesis H2b. Affect was measured with the PANAS system that lists positive and negative emotions, and people rate to what extent they feel that way at that exact moment, on a scale from 1 (not at all) to 5 (extremely). These measures are compiled into averages of the positive PANAS and negative PANAS scales.

First, I ran an ANOVA multiple regression test to regress positive affect onto culture, chroma, and hue on both main effects and interactions, as mediator effects. As expected from hypothesis $\mathrm{H} 2 \mathrm{~b}$ and the significant result of $\mathrm{H} 1$, culture group revealed a significant main effect on positive affect, such that Latinos reveal a higher positive affect after viewing the ad, although it was only marginally significant. The result of this mediation main effect showed a p-value between $0.05<\mathrm{p}<0.10$ with the statistics resulting in $\mathrm{f}(1,381)=3.538, \mathrm{p}=0.061$. This means that the Latino population had a higher mean of positive affect, or a better emotional reaction than Americans did after viewing the ad, regardless of chroma or hue levels. This is consistent with $\mathrm{H} 2 \mathrm{~b}$, as positive affect was predicted to be a mediator of any significant results from H1. All other 
relationships were not significant with $\mathrm{p}$ values greater than 0.10 , as consistent with the hypothesis and the results of H1. This mediation effect is further studied and developed in the mediation section, as it is an interesting finding that explains the significant culture effect of $\mathrm{H} 1 \mathrm{a}$ and $\mathrm{H} 1 \mathrm{~b}$.

Similarly, I ran an ANOVA multiple regression test to regress negative affect onto culture, chroma, and hue on both main effects and interactions. No significant results were expected from $\mathrm{H} 2 \mathrm{~b}$ for negative affect. Consistent with that, all relationships were not significant with $\mathrm{p}$ values greater than 0.10 .

\section{Mediation}

Given the significant results of culture affecting brand attitude and purchase intent, the mediation effect was important next, to understand the reason behind those significant relationships. The main effect of culture affecting brand perception and purchase intent were already proven significant in H1. Next, the same main effect of culture was proven to be significant on positive affect, one of the hypothesized mediators in H2. The next condition for the mediation effect is the effect of the mediator as an independent variable on the original dependent variables, brand attitude and purchase intent. I ran two ANOVA multiple regression tests to regress brand attitude and purchase intent onto positive affect. The result of the brand attitude mediation test was significant with a pvalue of $\mathrm{p}<0.05$ and the statistics resulting in $\mathrm{f}(20,368)=3.859, \mathrm{p}=0.000$. Similarly, the result of the purchase intent mediation test was significant with a $\mathrm{p}$-value of $\mathrm{p}<0.05$ and the statistics resulting in $\mathrm{f}(20,368)=7.435, \mathrm{p}=0.000$. This led to the final condition to prove the mediation effect, where the linear regression equation now tests both the original independent variable (culture) and the mediator (positive affect) on the original dependent variables (brand attitude and purchase intent). For the mediation effect to prove true, only the coefficient of the mediation needs 
to be significant, with the independent variable coefficient not being significant. This proved to be true for the mediation effect of positive affect on brand attitude, with the culture p-value being greater than 0.05 , and the positive affect p-value being less than 0.05 . The statistics for culture group were $\mathrm{t}=1.543, \mathrm{p}=0.124$, with the statistics for positive affect being $\mathrm{t}=7.715, \mathrm{p}=0.000$. This means that the mediation effect holds true, so the more positive feeling Latinos get after viewing the ad is the reason for their brand attitude ratings being higher. Furthermore, purchase intent as a mediator proved to be partially significant, as both coefficients for culture and positive affect were significant in the linear regression, with both p-values being less than 0.05 . The statistics for culture group were $\mathrm{t}=3.603, \mathrm{p}=.000$, with the statistics for positive affect being $\mathrm{t}=11.495, \mathrm{p}=0.000$. This means that the mediation effect of positive affect on purchase intent is true, but not a full explanation for the significance of culture group on purchase intent.

These significant mediation effect findings are consistent with hypothesis $\mathrm{H} 2 \mathrm{~b}$ that attributed $\mathrm{H} 1$ effects to positive affect after viewing the ad. The results mean that the reason why Latinos have a more favorable brand attitude is that they feel better than Americans after viewing the ad. Similarly, while the positive feeling Latinos get is a reason for their higher purchase intent, there is also something else that is causing this effect. This positive affect means that Latinos' favorable behavior and attitude towards the brand is coming from an emotional response, and not a cognitive response, as proved by ad recall testing. While in this study, I expected Latinos to react more positively to brands after viewing high chroma ads, in fact they reacted more positively to the ad in general, regardless of chroma or hue. After exploring potential reasons for why they liked the brand and why they are more willing to buy it, it resulted that the reason is a more positive emotive reaction to the ad. This emotive response can be attributed to aspects of the ad that affect emotion, like the brand name, ad content, or color. These attributes would need to be tested further to understand why Latinos reacted more positively. My prediction is still that Latinos react more 
positively because they are affected more by color, potentially on a dimension that was not tested in this study, since the quality of color was not significant. These dimensions could be value, hue, or simply the presence of color. 


\section{GENERAL DISCUSSION}

\section{Findings}

The rising diversity of cultures in the United States is of particular interest given that culture is a learned association that affects human perception. With the Hispanic population in the US as the largest and fastest growing minority consumer segment, it is important to understand how Hispanics perceive and react to marketing cues like color. Given an array of historical, metaphysic, and cultural factors, it is commonly believed that Latinos have a stronger preference for bright colors, but also that they react greatly to colors in general. In this study, I investigated the effect of chroma, the property that makes colors "bright", with culture, comparing Latinos living in the US to Americans, and how this interaction would affect their attitude and behavior. I expected the Latino population to have more favorable attitudes and behavior towards a brand after viewing a high saturation ad. This hypothesis was not fully supported, although there were very interesting, consistent findings.

Latinos proved to have overall more favorable brand attitudes and higher purchase intent than Americans, regardless of chroma or hue. This significant effect of culture on attitude and behavior was mediated significantly, or explained by Latinos' higher positive affect after viewing the ad. This is an interesting finding as these perception effects are formed by either emotion or cognition. In this study, cognition was tested with the ad recall measures and proven to be not significant. Also, emotion was tested and it proved to be significant, meaning that Latinos feel more positive after viewing the ad. That emotion proved to be an explanation for their favorable attitude and behavior.

This opens the question of why Latinos reacted more positive emotionally. Given that emotive responses to ads are driven by aspects of the ad like brand name (like SHINE), content of the ad (like the use of kiwi as a flossed fruit), product (like dental floss), or color, I would need to 
test for these other attributes next to identify the reason for the positive affect. My prediction is still that the reason is color, potentially other properties, like value or hue, or even just the presence of color. While this study proved that the quality of color was not significant, it is possible that other properties or the pure presence still affects Latinos emotionally. This suggested interpretation is due to the fact that color is a learned association that differs in the Latino culture, but it would need to be investigated. A way to test the effect of presence of color on emotion would be to remove color completely, and make the ad black and white. In this, I would expect Latinos' emotive reactions to decrease significantly more than Americans, and therefore behavior and attitude too, when color is removed. Additionally, I would expect other emotive attributes, like brand name, ad content, or type of product to have no significant effects, but this would also need to be tested in the future.

Furthermore, to prove more directly that cognition is not affecting perception differently for Latinos than Americans, I would change the cognitive aspects like the attributes recalled, and I would expect no difference here, consistent with the results of this study.

Another interesting finding of this study was an acculturation effect, partially seen from the significant negative correlation between years in the US for the Latinos and purchase intent. The more time the Latinos have been in the US, the less intent to purchase they have. This suggests that the effect of the ad is becoming weaker as they acculturate to the American society more, which further makes me think that color, as a cultural learned association, might be the reason for the emotive responses. This effect didn't prove significant for brand attitude so this initial evidence would need to be studied further.

The findings of Latinos reacting more positively to these ads in terms of feelings, attitudes, and behavior is a significant contribution to the research community, given that it has been proven that Latinos have different emotional and behavioral reactions to advertising, as compared to 
Americans. Additionally, the many inferences made about Latinos liking bright colors more than Americans is not scientifically true. That is important for marketers to know, as any decisions taken in terms of brightening colors for the Latino consumer group, as many companies have previously done, is futile as there is no proof backing those inferences. However, it is important to continue developing on this study as there is potential for actionable information on color or other ad and brand attributes that influence the Latino population. For example, if the presence versus absence of color results to be the reason for positive emotions, marketers can incorporate more color into their logos, packaging, advertisements, and more, when trying to sell to Latino consumers.

\section{Limitations and Future Work}

As is common in research, this study encountered limitations in the data collection, controls, and analyses. These effects were controlled to the best of my ability given the time and resource restraints. However, while none of these limitations are big enough to have compromised the quality of the results, it is still important to consider them to improve future development of this and other related work.

In the data collection, a limitation faced was that the ideal study design collection of 240 Latino and 240 American respondents had to be filtered out to get rid of responses that could have added external effects to the data. For example, Latinos born in an "Other" country, not one of the 23 Latin American countries listed in the survey, were kicked out to avoid potentially skewing the data. Additionally, about 15 respondents ended up being colorblind, so their data was also not included in the analysis. This reduced this study's actual sample to 158 Latinos and 231 Americans, which are sample sizes big enough for conclusive data, but lower than expected. 
Additionally, through an online collection survey, it was impossible to control for lighting of the computer of the respondents without giving away the purpose of the study. Having instructions would have skewed the responses by making respondents aware of the variables and topics of interest. While letting the natural differences cancel out to control for discrepancies through a large sample size was the best option for this study, it would be ideal and better controlled to have participants come into a room with controlled lighting and with controlled pigmentation and light of the ads through print or computer brightness.

Another limitation was the use of only one advertisement. The use of the same content might skew the results if someone has a predisposed notion or preference towards kiwis or dental floss. It would be better to vary the advertisement with different type of ads in terms of visuals, content, and products. More specifically, even the use of a kiwi was limited to an extent, because it is not as popular of a fruit. There were $15+$ responses that called the fruit a lemon, lime, avocado, cucumber or described it as a fruit they did not know in the recall section. Additionally, the product, dental floss, could cause skewing of the data since it is a pretty concentrated industry in terms of big players (Ex. Crest, Colgate, etc.), and if people are already attuned and loyal to a certain existing brand, they might have lower perceptions of this made-up brand, especially since it is a health product. Finally for the ad, while the brand name "Shine" was made up and does not exist, the word itself is an English word that makes sense for the product. In Spanish, the word can be read phonetically but it does not mean anything or flow phonetically as naturally as in English. It would be interesting to incorporate a variable of randomness to better control for the neutrality of the sound of the name, since that has proven to affect people's perceptions of brands in previous research. 
The last limitation faced was the nature of the limited data. In an ideal situation, the study could have continued to analyze the reasons why the effects found were significant beyond what was already determined. It is interesting to know that Latinos had a more positive brand attitude and higher purchase intent. However, once the positive affect was determined to be a significant mediator for brand perception, it would be interesting to figure out whether Latinos have a higher affect in general or if it was because of the ad. If it is because of the ad, it is important to next figure out which part of the ad, whether it was the content of the ad, color in general, or maybe even another property, like hue or value, of color. Additionally, in the future, other reasons for the higher purchasing intent will be studied as positive affect was only partially significant. A longer, more inclusive and extensive survey would allow for more of these questions to be studied.

In the future, it would also be interesting to re-run this experiment with other culture groups, or even Latinos outside of the US. It would also be interesting to study the same group and test with different potential mediators, or independent variables of color, like hue or value. Finally, it would be interesting too to look into reasons for the effects hypothesized not being significant, given all the research and cultural indications that led to the hypotheses. However, this study's significant results still open up many possibilities for future study, and allow replication through a comprehensive methodology, design, and analysis section. 


\title{
Exhibit 1: Cultures differ in their aesthetic expressions as colors represent different meanings and aesthetic appeals in different cultures
}

\author{
(Aslam 2006, Hupka et al 1997).
}

For instance, Blue the American corporate colour is perceived as cold and evil in East Asia (Schmitt 1995), but stands for warmth in Holland, coldness in Sweden, death in Iran, and purity in India (Schiffman et al. 2001). It denotes femininity in Holland but masculinity in Sweden and the United States (Neal et al. 2002). Blue represents high quality in the United States, Japan, South Korea and China, and also means sincere, trustworthy and dependable in Japan, South Korea and the U.S. (Jacobs et al. 1991).

Red is perceived to be unlucky and negative in Chad, Nigeria and Germany but lucky in China, Denmark, Romania and Argentina (Schmitt 1995; Neal et al. 2002). It is a bride's colour in China but a masculine colour in the U.K. and France (Neal et al. 2002). It symbolises ambition and desire in India (Kreitler and Kreitler 1972, cited in Grossman and Wisenblit 1999), and love in China, Korea, Japan and the U.S. (Jacobs et al. 1991).

Yellow represents warmth in the United States but infidelity in France (Neal et al. 2002). It is associated with envy and jealousy in Germany and with envy in Russia (Hupka et al. 1997), whereas in China yellow is considered pleasant, happy, good taste, progressive and is associated with authority, royalty, and trustworthiness (Jacobs et al. 1991; Schmitt 1995). Yellow is also associated with happiness in South Korea and Japan (Jacobs et al. 1991).

Green represents danger or disease in Malaysia (Ricks 1984). In Japan, green represents love, happiness, good taste and adventure (Oyama et al. 1963, cited in Hupka et al. 1997; Jacobs et al. 1991), whereas it represents envy in Belgium and the United States (Hupka et al. 1997). In China, green connotes sincere, trustworthy and dependable. Green also represents good taste and adventure in the United States (Jacobs et al. 1991).

Purple is related to anger and envy in Mexico and Poland (Hupka et al. 1997). Japanese connect purple with sin and fear (Oyama et al. 1963, cited in Hupka et al. 1997). Purple is a colour of love in China, South Korea and the U.S. It is considered as expensive in China, South Korea and Japan but as inexpensive in the U.S. (Jacobs et al. 1991).

Black is associated with dullness and stupidity in Indian culture (Kreitler and Kreitler 1972, cited in Grossman and Wisenblit 1999). It represents grief and sadness in the western cultures (Hupka et al. 1997), but it is also a ceremonial dress for priests and justices and a dress of subservience for lower class such as waiters and servants. Japanese connect black with fear (Oyama et al. 1963, cited in Hupka et al. 1997), whereas in Germany it represents fear, anger and jealousy. In Russia and the U.S. black is associated with fear, anger, envy and jealousy, whereas in Mexico with anger, envy and jealousy and in Poland with fear, anger and envy (Hupka et al. 1997). Black is seen as powerful and expensive in the U.S., China, Japan and South Korea and as dependable in both China and Japan. The Chinese also associate black with being trustworthy and high quality (Jacobs et al. 1991).

White symbolizes mourning or death in Japan, Far East and much of Asia (Ricks 1984), but happiness and purity in Australia, New Zealand and the U.S. (Neal et al. 2002). 


\section{Exhibit 2: Experimental Framework}

A) Study Design

\begin{tabular}{|c|c|c|}
\hline \multicolumn{3}{|c|}{ Americans } \\
\hline $2 \times 2 \times 2$ & Low Chroma & High Chroma \\
\hline Cool Hue & Anticipated & Anticipated \\
& Number of & Number of \\
Responses: 60 & Responses: 60 \\
\hline Warm & Anticipated & Anticipated \\
Hue & Number of & Number of \\
Responses: 60 & Responses: 60 \\
\hline
\end{tabular}

\begin{tabular}{|c|c|c|}
\hline \multicolumn{3}{|c|}{ Latinos } \\
\hline $2 \times 2 \times 2$ & Low Chroma & High Chroma \\
\hline Cool Hue & Anticipated & Anticipated \\
& Number of & Number of \\
Responses: 60 & Responses: 60 \\
\hline Warm & Anticipated & Anticipated \\
Hue & Number of & Number of \\
Responses: 60 & Responses: 60 \\
\hline
\end{tabular}

B) Survey \& Construct Design

\begin{tabular}{c|c|c|c|c|} 
& \multicolumn{2}{c}{ Americans } & \multicolumn{2}{c}{ Latinos } \\
\cline { 2 - 4 } Chroma Level: & $30 \%$ & $100 \%$ & $30 \%$ & $100 \%$ \\
\cline { 2 - 5 } Ad 1: Blue Cool Hue & 60 & 60 & 60 & 60 \\
\cline { 2 - 5 } Ad 2: Orange Warm Hue & 60 & 60 & 60 & 60 \\
\cline { 2 - 5 } & & & & \\
\hline
\end{tabular}




\section{Exhibit 3: Survey Advertisements}

Advertisement \#1: High Chroma, Cool Color Hue

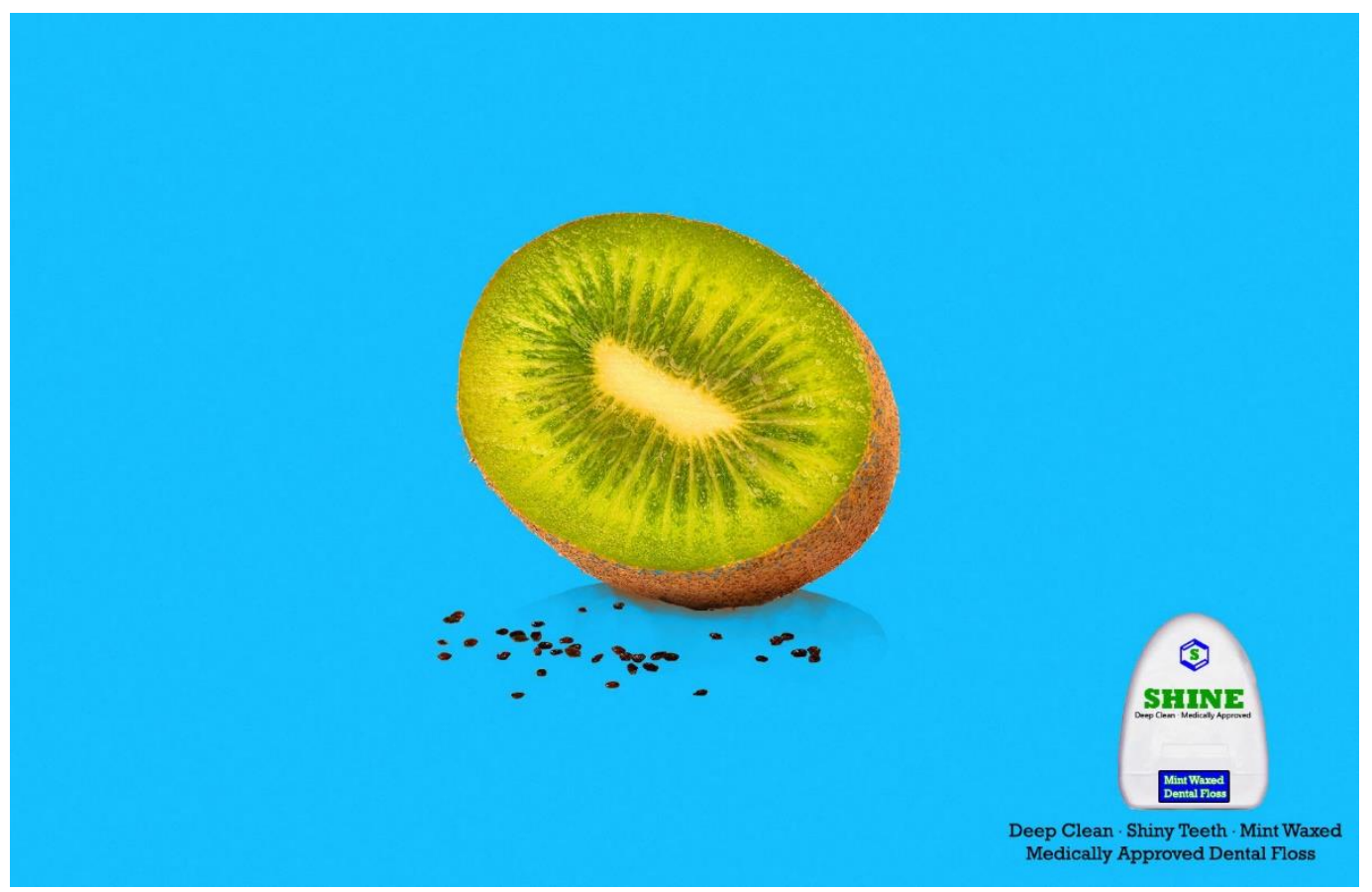

Advertisement \#2: High Chroma, Warm Color Hue

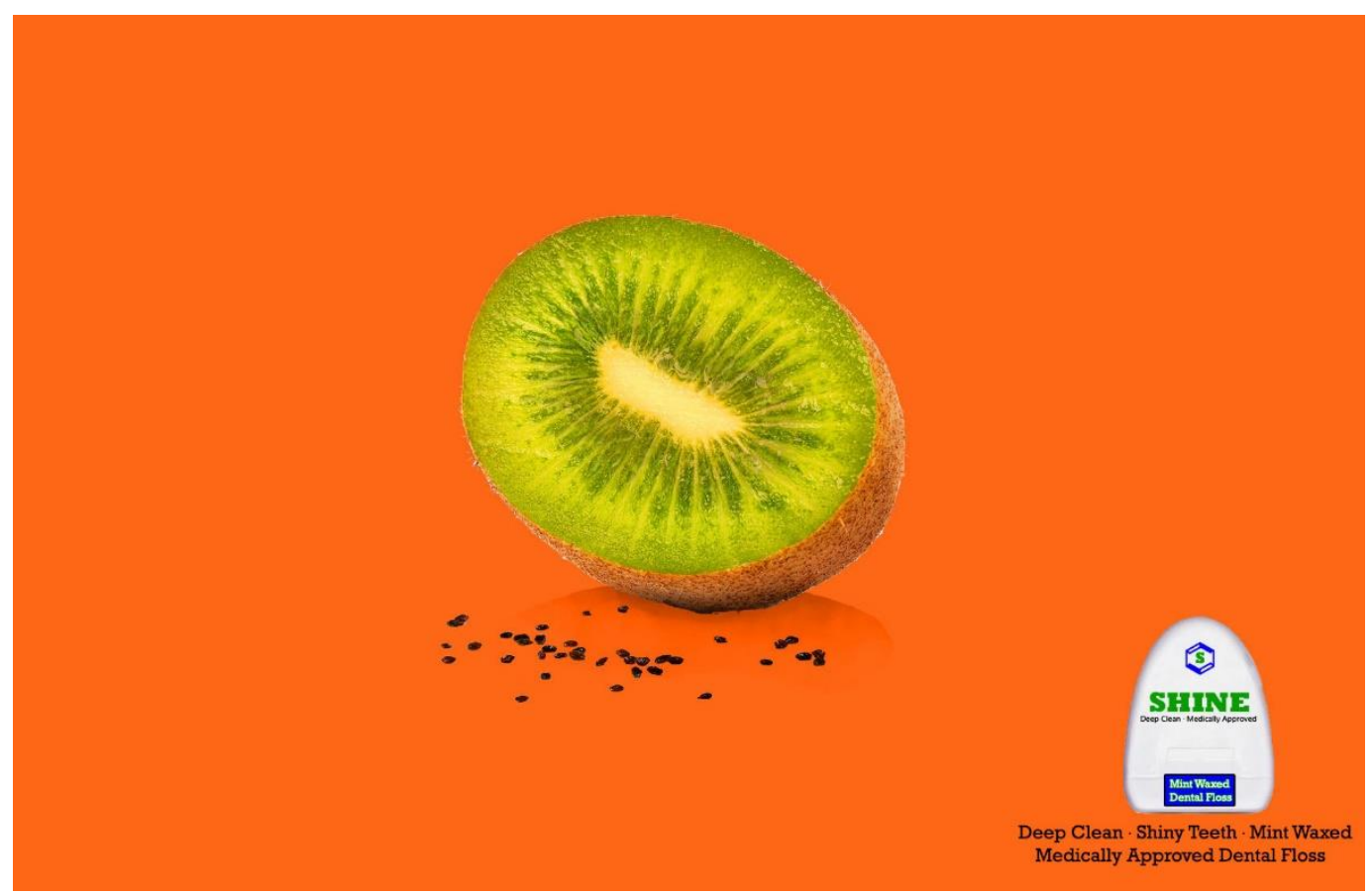




\section{Exhibit 3 (continued): Survey Advertisements}

Advertisement \#3: Low Chroma, Cool Color Hue

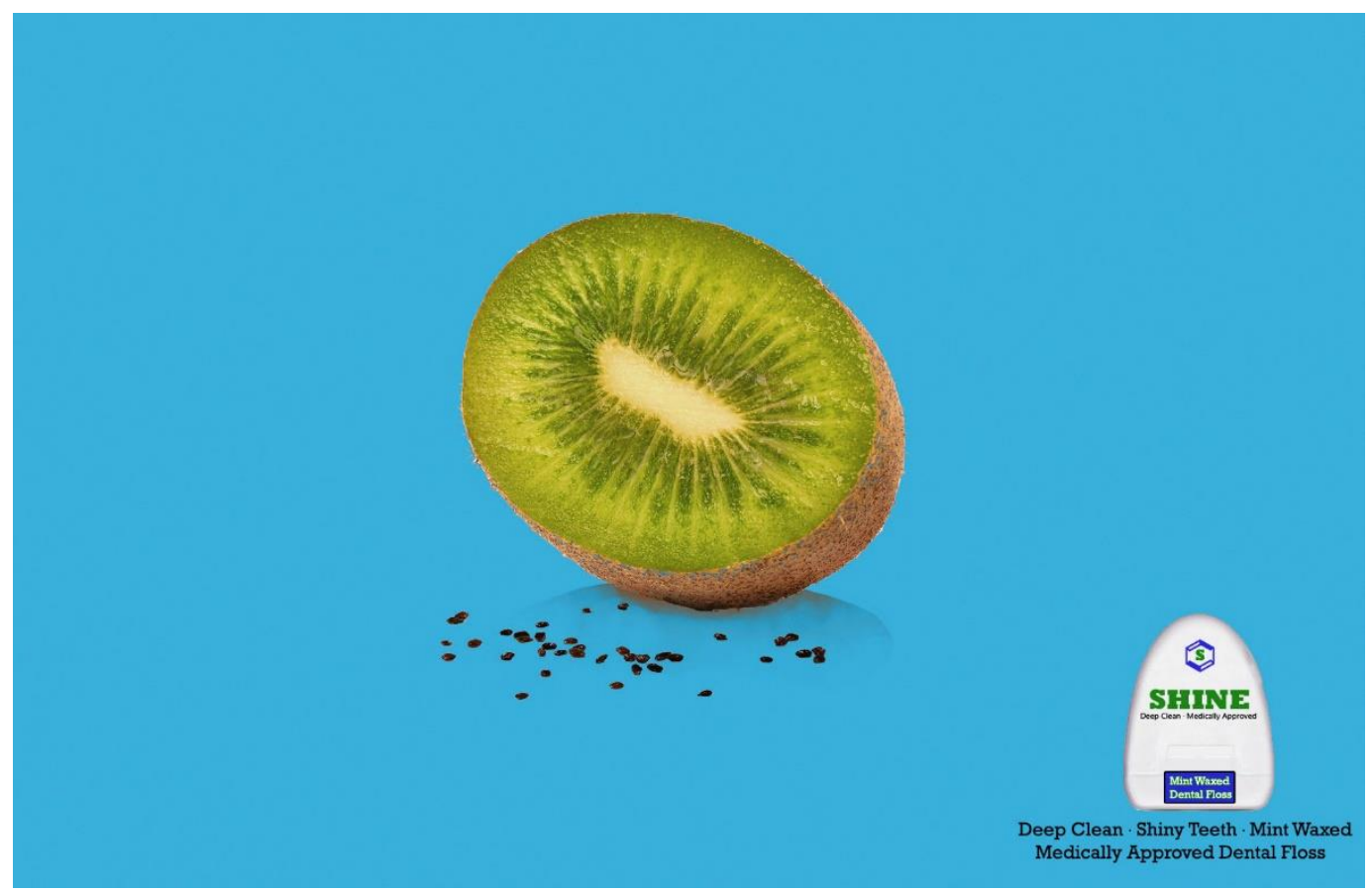

Advertisement \#4: Low Chroma, Warm Color Hue

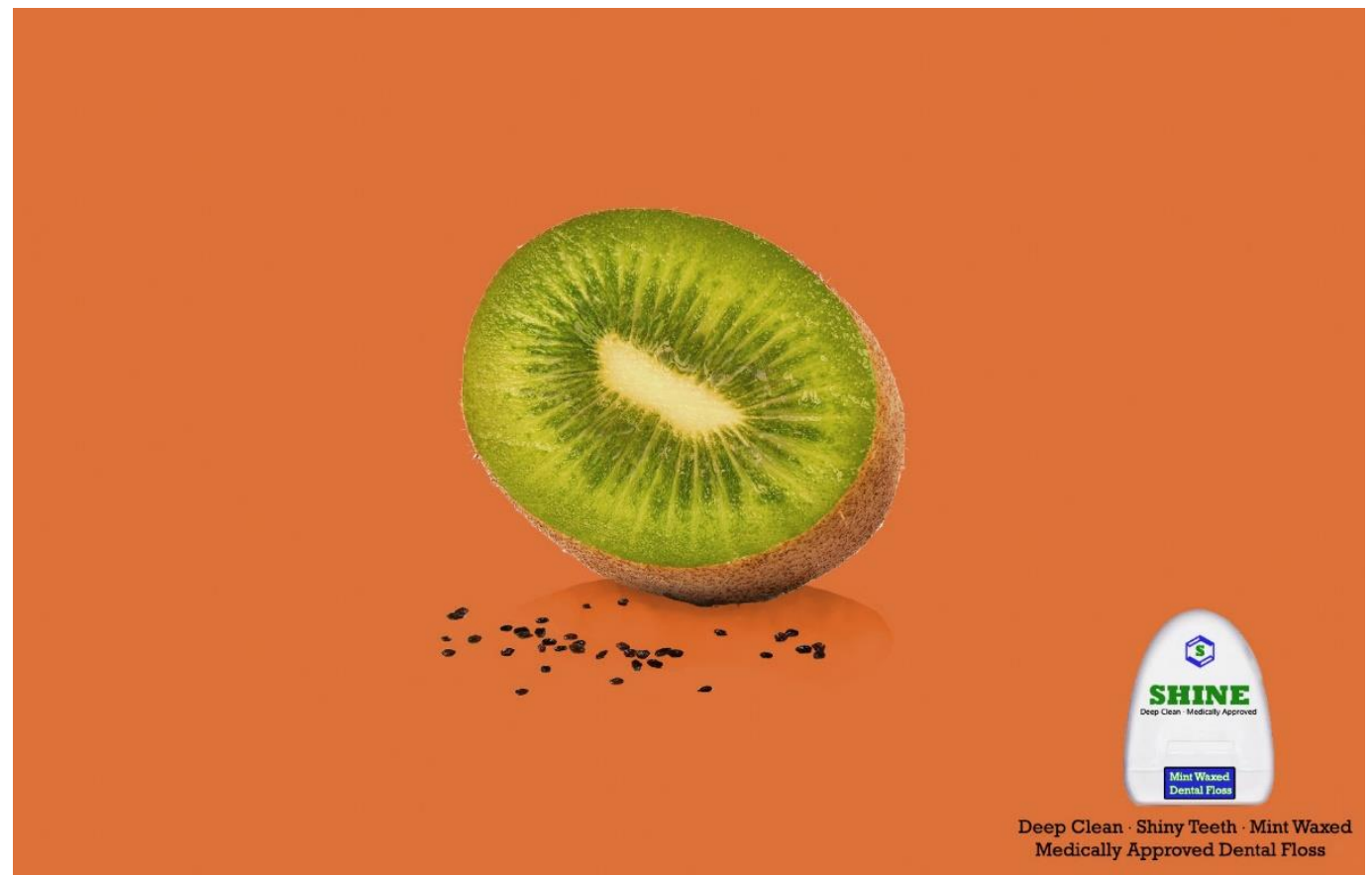




\begin{tabular}{|c|c|}
\hline \multicolumn{2}{|r|}{ Exhibit 4: Survey questions } \\
\hline Constructs & Item \\
\hline Brand Attitude & $\begin{array}{l}\text { Bad/Good (Spears \& Singh) (1-7) } \\
\text { Unpleasant/Pleasant (Spears \& Singh) (1-7) } \\
\text { Unfavorable/Favorable (Spears \& Singh) (1-7) }\end{array}$ \\
\hline Purchase Intent & $\begin{array}{l}\text { Likelihood to purchase this product? (Zafar \& Rafique) ( } 1=\text { very unlikely }-7=\text { very likely) } \\
\text { Likelihood to actively seek out this product in a store? (Zafar \& Rafique) }(1-7)\end{array}$ \\
\hline Ad Recall & List everything that you recall from the ad (Gardner, Montgomery) \\
\hline Ad Attributes & $\begin{array}{l}\text { Quality rating of the following attributes from the advertisement: (Gorn et al.) (very good }(+4)-\text { very bad }(-4) \text { ) } \\
\text { Picture } \\
\text { Colors } \\
\text { Text font } \\
\text { Spacing } \\
\text { Wording }\end{array}$ \\
\hline Feelings & 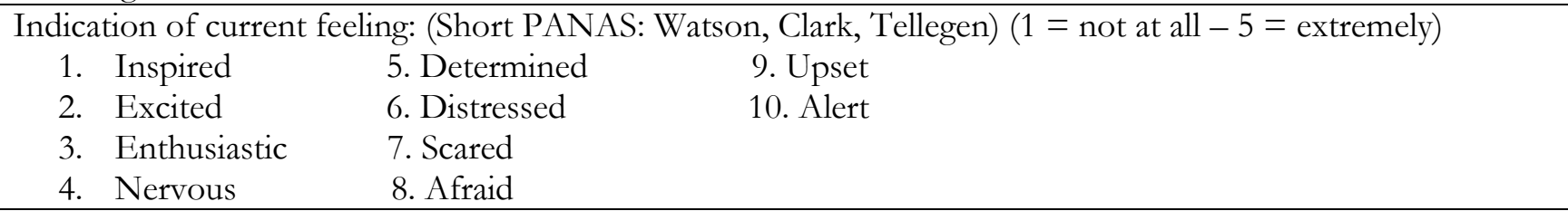 \\
\hline Consumer demographics & $\begin{array}{l}\text { Age (Zafar \& Rafique) } \\
\text { Gender (Male/Female) (Zafar \& Rafique) } \\
\text { Income (25,000 or less, 26-50,000, 51-75,000, 76-100,000, 101-125,000, 126,000 or more) (Zafar \& Rafique) } \\
\text { Age at which you arrived to the US (Friedberg) } \\
\text { Colorblindness (Gorn et al.) } \\
\text { Current state of residence (Zafar \& Rafique) } \\
\text { Country of birth (Zafar \& Rafique) }\end{array}$ \\
\hline
\end{tabular}

**All questions were adapted from the cited researchers and an integration of researcher Professor Nicole Montgomery's work. 


\section{BIBLIOGRAPHY}

1. Akcay, O., Sable, P., \& Dalgin, M. H. (2012, March). The Importance of Color In Product Choice Among Young Hispanic, Caucasian, and African-American Groups in the USA. International Journal of Business and Social Science Kutztown University of Pennsylvania, 3(6). doi:http://www.ijbssnet.com/journals/Vol_3_No_6_Special_Issue_March_2012/1.pdf

2. Aslam, Mubeen M. "Are you selling the right colour? A cross-cultural review of colour as a marketing cue." Journal of marketing communications 12.1 (2006): 15-30.

3. Bayón, Damián. "Art, c. 1920-c. 1980". In: Leslie Bethell (ed.), A cultural history of Latin America. Cambridge: University of Cambridge, 1998, pp. 393-454.

4. Bleakley H, Chin A. Age at arrival, English proficiency, and social assimilation among U.S. immigrants. Am Econ J Appl Econ. 2010;2(1):165-192.

5. Buhrmester, M., Kwang, T., \& Gosling, S. (2011, January). Amazon's Mechanical Turk A New Source of Inexpensive, Yet High-Quality, Data? [Scholarly project]. In Perspectives of Psychological Science. Retrieved November 27, 2016, from http://pps.sagepub.com/content/6/1/3.short

6. Dupey García, É. (2015, October 11). Colour and Culture Among the Aztecs. Retrieved November 27, 2016, from http://www.mexicolore.co.uk/aztecs/home/colour-and-cultureamong-the-aztecs

7. FFF: Hispanic Heritage Month 2015. (2015, September 14). Retrieved October 10, 2016, from http://www.census.gov/newsroom/facts-for-features/2015/cb15-ff18.html

8. Finholm, V. (2005, September 5). Brighter Paint Palette Aims At Hispanic Consumers. Retrieved November 27, 2016, from http:/ /articles.courant.com/2005-0930/features/0509290329_1_home-depot-hispanic-consumers-paint

9. Fitch, L. (2011, May 17). Hispanic marketing: Better by design. Retrieved November 27, 2016, from http:/ / latinobrandingpower.com/2011/05/17/hispanic-marketing-better-by-design/

10. Friedberg, R. (1992, December). The Labor Market Assimilation of Immigrants in the United States: The Role of Age at Arrival [Scholarly project]. In Brown.edu. Retrieved November 27, 2016, from

http://www.brown.edu/Departments/Economics/Faculty/Rachel_Friedberg/Links/Friedberg Age at Arrival.pdf

11. Garcia-Navarro, L. (2015, August 27). Hispanic Or Latino? A Guide For The U.S. Presidential Campaign. Retrieved November 27, 2016, from http:/ / www.npr.org/sections/parallels/2015/08/27/434584260/hispanic-or-latino-a-guide-forthe-u-s-presidential-campaign

12. Gardner, M. P. (1983, December). Advertising Effects on Attributes Recalled and Criteria Used for Brand Evaluations [Scholarly project]. In Journal of Consumer Research. Retrieved November 27, 2016, from http://www.jstor.org/stable/2488803?seq=1\#page_scan_tab_contents 
13. Gorn, Gerald J., et al. "Effects of color as an executional cue in advertising: They're in the shade." Management science 43.10 (1997): 1387-1400.

14. Heath, T., \& Gaeth, G. (n.d.). Theory and Method in the Study of Ad and Brand Attitudes: Toward a Systematic Model. Retrieved November 27, 2016, from https://books.google.com/books?hl=en\&lr=\&id=s8q3PHM9hiQC\&oi=fnd\&pg=PA125\&dq= rate how much you liked the attributes of the advertisement\&ots $=g g 0 \mathrm{XpuD} 4 \mathrm{U}-$ \&sig=RanWOz6kpapYoyKbmiGUDxOiKHg\#v=onepage\&q=rate how much you liked the attributes of the advertisement\&f=false

15. Huff, C., \& Tingley, D. (2015, Summer). "Who are these people?" Evaluating the demographic characteristics and political preferences of MTurk survey respondents [Scholarly project].

In Harvard Scholar. Retrieved November 27, 2016, from http://scholar.harvard.edu/dtingley/files/whoarethesepeople.pdf

16. Hupka, Ralph B., Zbigniew Zaleski, Jurgen Otto, Lucy Reidl, and Nadia V. Tarabrina. "The Colors of Anger, Envy, Fear, Jealousy: A Cross Cultural Study." Journal of Cross-Cultural Psychology 1997 Western Washington University 28.2 (1997): 156-71. Print.

17. Korzenny, F. (2009, Spring). Study of Multicultural Color Preferences [Scholarly project]. In Nkates Worldpress. Retrieved November 27, 2016, from https://nkates.files.wordpress.com/2012/05/final-research-report-studying-multicultural-colorpreferences.pdf

18. Krishna, Aradhna, ed. Sensory Marketing: research on the sensuality of products. Routledge, 2011.

19. Krishna, Aradhna. "An integrative review of sensory marketing: Engaging the senses to affect perception, judgment and behavior." Journal of Consumer Psychology 22.3 (2012): 332-351.

20. Labrecque, Lauren I., Vanessa M. Patrick, and George R. Milne. "The marketers' prismatic palette: A review of color research and future directions." Psychology \& Marketing 30.2 (2013): 187-202.

21. Ohno, Yoshi (16 October 2000). CIE Fundamentals for Color Measurements (PDF). IS\&T NIP16 Intl. Conf. on Digital Printing Technologies. pp. 540-45. Retrieved 2009-06-18.

22. Paul, P. (2002, February 01). Color by numbers. Retrieved November 27, 2016, from http://adage.com/article/american-demographics/color-numbers/43815/

23. Saunders, M., \& Tosey, P. (2013, Winter). The Layers of Research Design. The Association for Neuro Linguistic Programming (ANLP). Retrieved November 27, 2016, from http://www.anlp.org/files/research-onion-layers_42_357.pdf

24. Scaling: Semantic differential. (n.d.). Retrieved November 27, 2016, from http://psc.dss.ucdavis.edu/sommerb/sommerdemo/scaling/semdiff.htm

25. Spears, N., \& Singh, S. (2004, September). Measuring Attitude Toward the Brand and Purchase Intentions [Scholarly project]. In ResearchGate. Retrieved November 27, 2016, from file:///C:/Users/Faby/Downloads/Measuringattitude toward the brand.pdf

26. State of the Hispanic Consumer: The Hispanic Market Imperative (Rep.). (2012, Spring). Retrieved October 10, 2016, from The Nielsen Company website: 
http://www.nielsen.com/content/dam/corporate/us/en/reports-downloads/2012-

Reports/State-of-the-Hispanic-Consumer.pdf

27. Tej Adidam, P., \& Reizgeviciute, A. (n.d.). The Importance of Color in Global Marketing [Scholarly project]. In NSSA. Retrieved November 27, 2016, from

http://www.nssa.us/journals/2007-28-2/2007-28-2-02.htm

28. Thomas J. Madden, Kelly Hewett, Martin S. Roth (2000) Managing Images in Different Cultures: A Cross-National Study of Color Meanings and Preferences. Journal of International Marketing: Winter 2000, Vol. 8, No. 4, pp. 90-107.

29. Watson, D., \& Clark, L. A. (1988). Development and Validation of Brief Measures of Positive and Negative Affect: The PANAS Scales [Scholarly project]. In Journal of Personality and Social Psychology. Retrieved November 27, 2016, from http://www.cnbc.pt/jpmatos/28.Watson.pdf

30. Watson, D., \& Clark, L. A. (2016). Positive and Negative Affect Schedule (PANAS). Retrieved November 27, 2016, from http://www.statisticssolutions.com/positive-and-negative-affectschedule-panas/ 